\title{
Partially and non-destructive testing of 40 concrete bridges
}

\author{
S. M. A. Tajalli and S. R. Rigden
}

D. Doran, Consulting Civil and Structural Engineer

The authors are to be congratulated on their paper, the contents of which will be most valuable to the profession. I was particularly interested in the statements in paragraph 7 concerning the origins of failure. They compare interestingly with those quoted in Dr Alistair Paterson's paper given at his presidential address (see Reference 14 and Fig. 27).

\section{Author's reply}

The authors wish to thank D. Doran for his contribution, the valuable data presented in graphs, and comment that Paterson (1984), reported: in the UK information is not generally readily available on defects in building structures, but some statistics are available in France.
Paterson gives some results of building defects from the statistics gathered in France consisting on 10000 defects that occurred during 1968 to 1978 . The results of this data showed that $43 \%$ of the cost of repairs in this period was spent on remedies arising from faults caused by insufficient design consideration. Fifty nine percent of the faults caused by insufficient design consideration were found to be mainly due to poor design detailing. Forty three percent of the cost of repairs; were spent on repairing the faults caused by poor construction. Sixty percent of these faults were however observed within three years of completing construction.

\section{REFERENCE}

14. Paterson A. C. Presidential address. The Structural Engineer, 1984, 62A, No.11, 335-342.

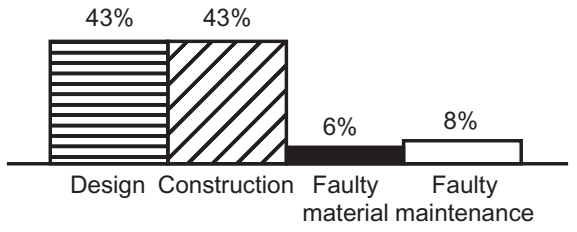

(a)

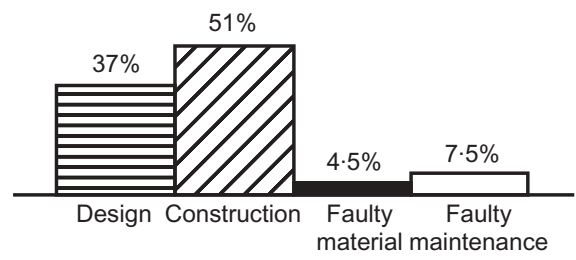

(b)

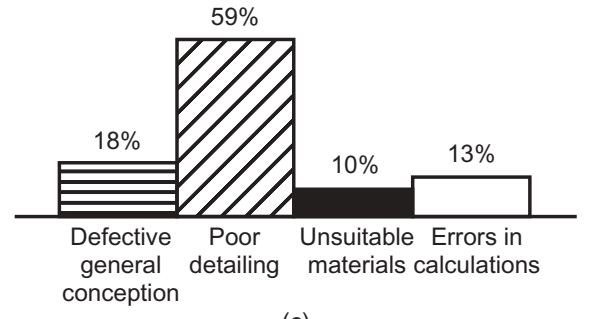

(c)

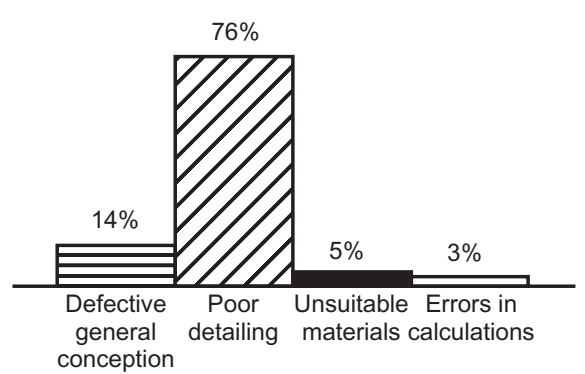

(d)

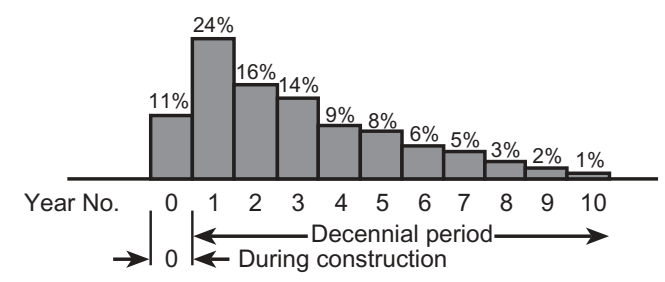

(e)

Fig. 27. Causes of defects in buildings are gathered in France consisting of 10000 defects that occured during 1968-1978: (a) causes of defects in terms of cost of repair; (b) causes of defects in terms of frequency of occurrence; (c) cuases of design faults in terms of cost; (d) causes of design faults in terms of frequency of occurrence; (e) building defects in the first ten years (This figure is reproduced from Construction Disputes, $P$. Campbell (ed.), courtesy of Whittles Publishing) 